Article

\title{
Isolation Improvement in UWB-MIMO Antenna System Using Slotted Stub
}

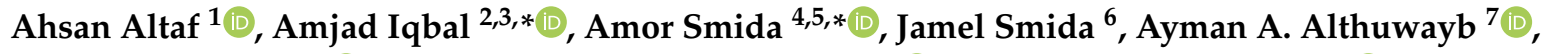 \\ Saad Hassan Kiani ${ }^{8}$ (D), Mohammad Alibakhshikenari ${ }^{9, *(D)}$ and Francisco Falcone ${ }^{10,11^{(D)}}$ \\ and Ernesto Limiti ${ }^{9}$ (D) \\ 1 Electrical Engineering Department, Istanbul Medipol University, Istanbul 34083, Turkey; \\ aaltaf@st.medipol.edu.tr \\ 2 Centre For Wireless Technology, Faculty of Engineering, Multimedia University, Cyberjaya 63100, Malaysia \\ 3 Electrical Engineering Department, CECOS University of IT and Emerging Sciences, \\ Peshawar 25000, Pakistan \\ 4 Department of Medical Equipment Technology, College of Applied Medical Sciences, Majmaah University, \\ AlMajmaah 11952, Saudi Arabia \\ 5 Microwave Electronics Research Laboratory, Department of Physics Faculty of Mathematical, \\ Physical and Natural Sciences of Tunis, Tunis ElManar University, Tunis 2092, Tunisia \\ 6 College of Applied Sciences, AlMaarefa University, Riyadh 11952, Saudi Arabia; jsmida@mcst.edu.sa \\ 7 Electrical Engineering Department, Jouf University, Sakaka, Aljouf 72388, Saudi Arabia; \\ aaalthuwayb@ju.edu.sa \\ 8 Department of Electrical Engineering, City University of Science and Information Technology, \\ Peshawar 25000, Pakistan; iam.kiani91@gmail.com \\ 9 Electronic Engineering Department, University of Rome “Tor Vergata", Via del Politecnico 1, \\ 00133 Rome, Italy; limiti@ing.uniroma2.it \\ 10 Electrical Engineering Department, Public University of Navara, 31006 Pamplona, Spain; \\ francisco.falcone@unavarra.es \\ 11 Institute of Smart Cities, Public University of Navarre, 31006 Pamplona, Spain \\ * Correspondence: amjad730@gmail.com (A.I.); a.smida@mu.edu.sa (A.S.); \\ Alibakhshikenari@ing.uniroma2.it (M.A.); Tel.: +60-1-128-78-4475 (A.I.)
}

Received: 11 September 2020; Accepted: 25 September 2020; Published: 27 September 2020

check for updates

\begin{abstract}
Multiple-input multiple-output (MIMO) scheme refers to the technology where more than one antenna is used for transmitting and receiving the information packets. It enhances the channel capacity without more power. The available space in the modern compact devices is limited and MIMO antenna elements need to be placed closely. The closely spaced antennas undergo an undesirable coupling, which deteriorates the antenna parameters. In this paper, an ultra wide-band (UWB) MIMO antenna system with an improved isolation is presented. The system has a wide bandwidth range from 2-13.7 GHz. The antenna elements are closely placed with an edge to edge distance of $3 \mathrm{~mm}$. In addition to the UWB attribute of the system, the mutual coupling between the antennas is reduced by using slotted stub. The isolation is improved and is below $-20 \mathrm{~dB}$ within the whole operating range. By introducing the decoupling network, the key performance parameters of the antenna are not affected. The system is designed on an inexpensive and easily available FR-4 substrate. To better understand the working of the proposed system, the equivalent circuit model is also presented. To model the proposed system accurately, different radiating modes and inter-mode coupling is considered and modeled. The EM model, circuit model, and the measured results are in good agreement. Different key performance parameters of the system and the antenna element such as envelope correlation coefficient (ECC), diversity gain, channel capcity loss (CCL) gain, radiation patterns, surface currents, and scattering parameters are presented. State-of-the-art comparison with the recent literature shows that the proposed antenna has minimal dimensions, a large bandwidth, an adequate gain value and a high isolation. It is worth noticeable that the proposed antenna has high isolation even the patches has low edge-to-edge gap $(3 \mathrm{~mm})$. Based on its good performance
\end{abstract}


and compact dimensions, the proposed antenna is a suitable choice for high throughput compact UWB transceivers.

Keywords: isolation enhancement; surface waves; gain; circuit model; slotted-stub; MIMO antennas

\section{Introduction}

In the last decade, mobile technology enables researchers to find solutions for systems consist of multiple devices, sensors, and components [1-5]. Antennas are one of the important components of these multi-device systems [6-8]. With MIMO technology, need for antennas that can operate over a wide range of frequencies is inevitable [9-12]. Ultra wide band (UWB) antennas have better channel capacity, envelope correlation, and diversity gain as compared to traditional narrowband antennas [13].

According to Federal Communication Commission (FCC) protocol, the UWB ranging from 3.2 to 10.6 GHz covering indoor applications and handheld devices [14]. Several designs have been proposed and researched in [15-19] for UWB services. In [15] a V shape monopole antenna with staircase shaped defected ground structure is proposed having realized gain of $4 \mathrm{~dB}$ with size of $25 \times 26 \mathrm{~mm}$ for UWB applications. The Multiple Input Multiple Output (MIMO) technology offers higher data rates with better propagation response in multipath propagating environment and noise immunity [20-22]. Enhanced Isolation is desirable in MIMO antenna systems as the lower coupling ensures the better antenna performance characteristics [23,24]. In order to suppress surface waves of MIMO radiating elements the use of defected ground structures (DGSs) [25,26], electromagnetic band gap structures (EBGs) [27,28], and line resonators [29] are commonly used.

In [30] an UWB MIMO antenna having dual notch response is investigated by using several metal strips with modified ground plane to reduce mutual coupling between the radiating elements. In [31] an UWB MIMO antenna with compact size $\left(25 \times 40 \mathrm{~mm}^{2}\right)$ and polarization diversity is presented. The design is complex because of two different ground planes. In [32] a bio inspired leaf shaped antenna is presented for wideband and sensing applications, however with a large dimensional size of $314 \times 121 \mathrm{~mm}$. The design is not suitable for MIMO configuration for handheld devices. The use of black carbon film on the UWB MIMO reduced the coupling effects in [33] due to absorption losses, however the cost of the system with such an approach increases.

In this paper, an UWB MIMO antenna system for 2-13.7 GHz is presented. The system is composed of two radiating elements. The mutual coupling between the antennas is reduced by using slotted stubs. The isolation is improved and is below $-20 \mathrm{~dB}$ for the whole operating range. The system is fabricated on an easily available, inexpensive, and widely used FR4 substrate. The system is designed using a EM full-wave commercial software HFSS. A detailed study regarding the antenna design, decoupling network, and other parameters of the design is presented. The circuit model is presented to verify the EM model. A prototype is fabricated to verify the simulated results. The comaprison between the simulated and measured results is presented and it is found that they are in good agreement. The effects of decoupling network over the performance of the antennas and the MIMO system is also studied. It is found that ECC and Diversity Gain (DG) for the proposed system are 0.15 and $9.85 \mathrm{dBi}$ respectively. The channel capcity loss (CCL) is less than $0.06 \mathrm{bps} / \mathrm{Hz}$ for the whole operating bandwidth.

\section{Design Methodology}

The design and prototype models of the proposed UWB MIMO antenna system are presented in Figure 1. The system is designed on an FR4 substrate with a thickness of $1.6 \mathrm{~mm}$. The dielectric constant of the substrate is assumed to be 4.4. The top side includes two radiating stepped-shaped elements with a $50 \Omega$ feed line. The stepped shape is designed to increase the path for the flow of current. By increasing the path for the current, a wide bandwidth is achieved. The two rectangles 
are designed at the top of each element to achieve wide-band matching. A rectangular ground plane with a rectangular slot is designed at the back side of the substrate. The antenna elements share a common ground plane. The upper edge of the common ground is stepped and incorporated with the plus-shaped slotted stubs to improve isolation between the antenna elements. The stubs act as a bandstop filter for the desired frequency range. It produces transmission zeros within the radiating elements that in turn disturb the flow of current, surface waves, and near fields. The dimensions of the antenna elements, slotted stubs, ground plane, and feed lines are shown in Figure 1.
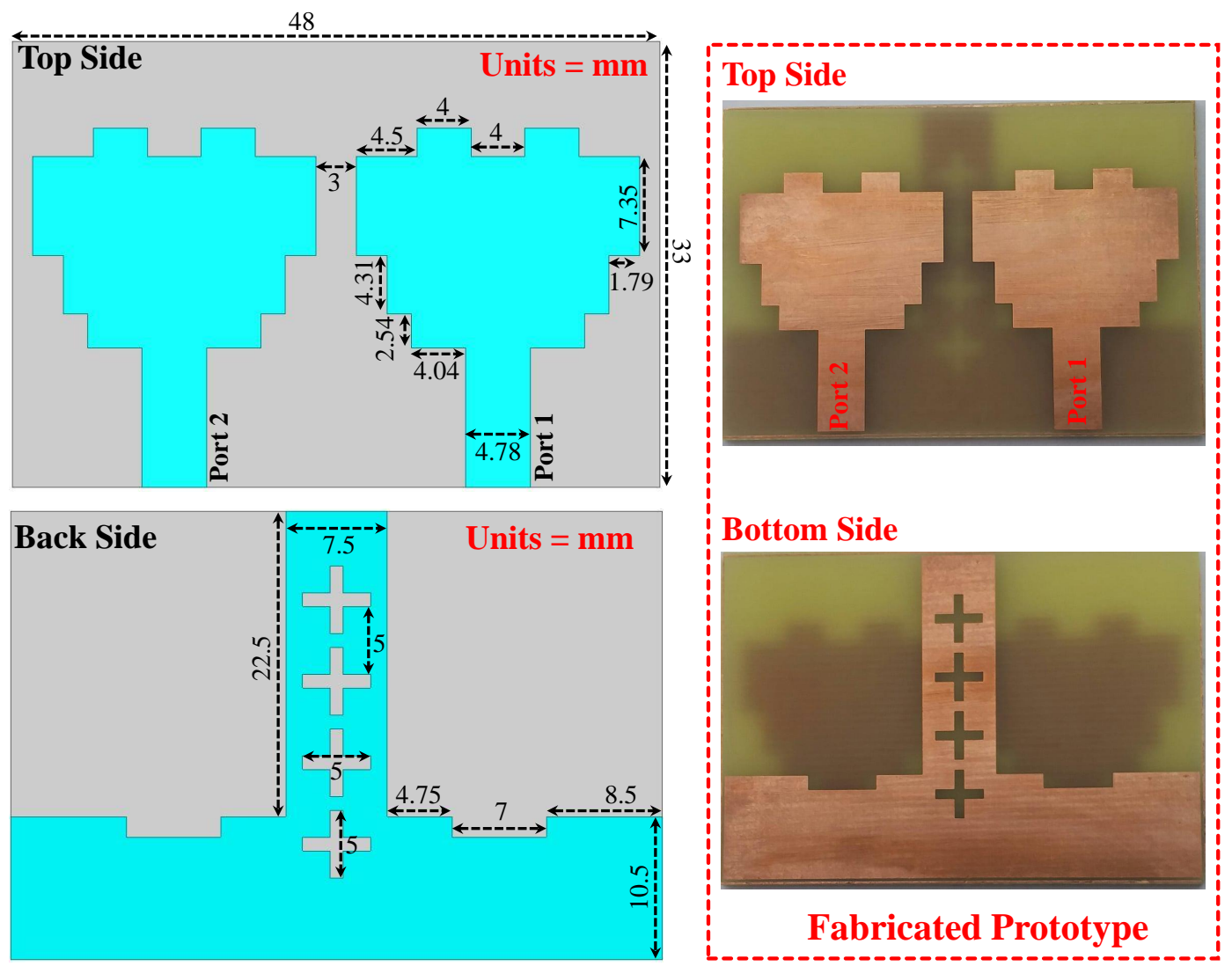

Figure 1. Top and bottom view of the proposed ultra wide-band multiple input multiple output (UWB-MIMO) antenna.

\subsection{Single Unit Antenna}

A detailed evolution procedure for the proposed setup is presented in Figure 2. In Step 1, a stepped-shaped single element with a slotted ground plane is designed. The ground plane covers the area between the lower edge and the feed line. In Step-2, two radiating elements with a common ground plane is designed. In other words, step- 1 is replicated along the $x$-axis to get a MIMO antenna system. The edge to edge distance between the antenna elements is $3 \mathrm{~mm}$. In the final step, slotted stubs are incorporated at the back side within the antenna elements to reduce the mutual coupling between the radiating elements. The slotted stubs suppress the surface waves and the near fields reducing the coupling between the antennas keeping it below $-20 \mathrm{~dB}$ for the whole desired frequency range. The step-by-step evolution of the proposed setup is shown in Figure 2. To understand the proposed MIMO antenna system, an equivalent circuit model for a single antenna using lumped elements is presented. In Figure 3 the transmission line is modeled as an impedance transformer with the coupling ratio of X1:1 in the circuit model. Since patch antenna is a resonating circuit, one can use circuit theory to model the radiating element approximately by the RLC circuit [34]. Where R is the radiation resistance of the radiating mode of the antenna, and $\mathrm{L}$ and $\mathrm{C}$ describe the resonant circuit that is responsible for the desired resonant frequency. The proposed antenna setup is a wide-band, therefore 
the desired response is a combination of different radiating modes. In addition to the combination of these radiating modes, the coupling between the modes should also be included to model the system accurately. The equivalent circuit model for a single element is shown in the inset of Figure 3 . The radiating modes are modeled by RLC combinations while the two LC (tank-circuits) combinations represent inter-mode coupling [35,36]. The circuit model is studied in Keysight Advance Design System (ADS). The values of each component and the comparison of S-parameters between the EM and the circuit model are depicted in Figure 3. The results are in good agreement.

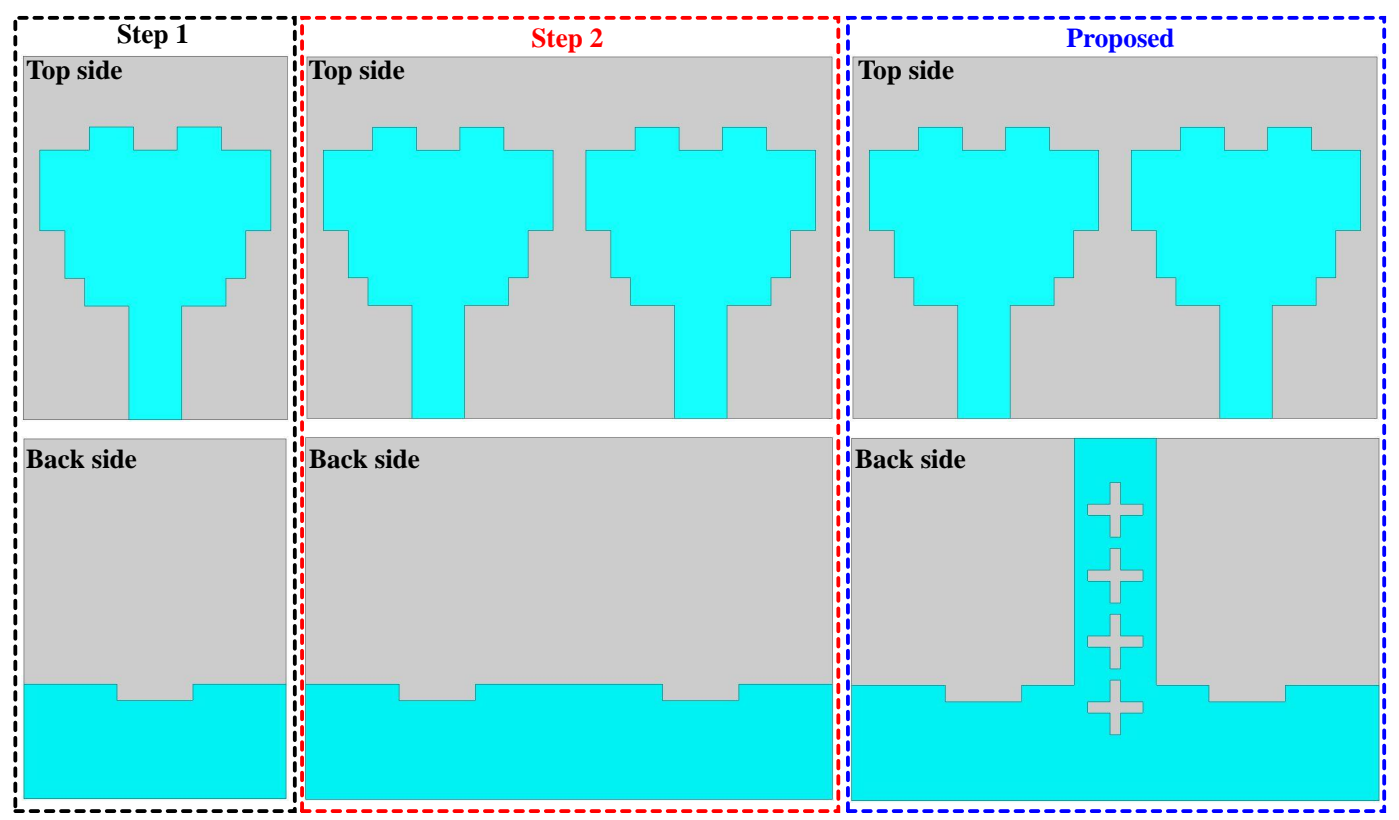

Figure 2. Design evolution stages of the proposed UWB-MIMO antenna.

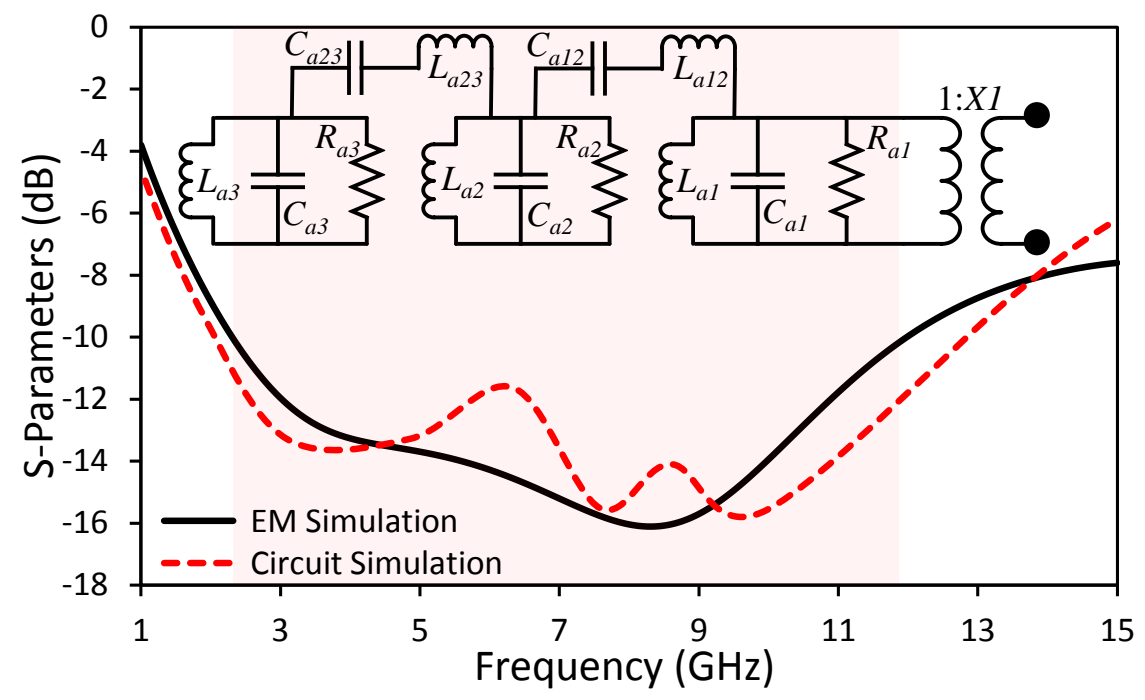

Figure 3. Lumped element equivalent circuit model $\left(R_{a 1}=295 \Omega, R_{a 2}=54.45 \Omega, R_{a 3}=60 \Omega\right.$, $C_{a 1}=3.45 \mathrm{pF}, C_{a 2}=3.82 \mathrm{pF}, C_{a 3}=4.8 \mathrm{pF}, L_{a 1}=1.55 \mathrm{nH}, L_{a 2}=7.42 \mathrm{nH}, L_{a 3}=3.85 \mathrm{nH}, L_{a 12}=0.6 \mathrm{nH}$, $C_{a 12}=1.5 \mathrm{pF}, L_{a 23}=0.7 \mathrm{nH}$ and $C_{a 23}=1.22 \mathrm{pF}$ ) and comparison of EM and circuit model results.

\subsection{UWB-MIMO Antenna System without Slotted Stub}

In this section, the circuit model for the proposed MIMO antenna system is presented. As discussed in the previous section, each antenna element can be modeled as a combination of the RLC circuit, and a feed line can be modeled as an impedance transformer. Since our antennas exhibit wide-band response, many radiating modes are contributing. In other words, a combination 
of radiating modes makes it a wide-band antenna. From circuit theory, it is evident that inter-mode coupling affects the response of the circuit. Therefore, to model the MIMO antenna system accurately, one should not only consider the radiating modes but also the inter-mode coupling. In this paper, for simplicity, three radiating modes and inter-mode coupling between antennas are considered for corresponding modes only. For instance, the coupling between mode- 1 of antenna- 1 with mode- 1 of antenna- 2 is considered but the coupling of mode- 1 of antenna- 1 with the coupling of mode- 2 of antenna- 2 is not discussed. The equivalent circuit model of the proposed system without slotted stubs is shown Figure 4. The feed lines of the radiating elements are modeled by impedance transformers with a coupling ratio of X1:1. Each antenna element radiating modes are modeled by a combination of RLC circuits while the tank circuits represent the inter-mode couplings. The mutual coupling between the corresponding radiating mode of antenna elements is represented by $M_{1}, M_{2}$, and $M_{3}$. The circuit model is designed in ADS. The comparison for S-parameters results between the EM and the circuit model and the values of each component are shown Figure 5. It can be seen from Figure 5, the results are in a good agreement for the desired frequency band.

\begin{tabular}{|c|c|}
\hline Component & Value \\
\hline$R_{a 1}$ & $1546 \Omega$ \\
\hline$R_{a 2}$ & $1861 \Omega$ \\
\hline$R_{a 3}$ & $47 \Omega$ \\
\hline$C_{a 1}$ & $0.5 \mathrm{pF}$ \\
\hline$C_{a 2}$ & $0.5 \mathrm{pF}$ \\
\hline$C_{a 3}$ & $10.45 \mathrm{pF}$ \\
\hline$L_{a 1}$ & $0.5 \mathrm{nH}$ \\
\hline$L_{a 2}$ & $0.5 \mathrm{nH}$ \\
\hline$L_{a 3}$ & $0.93 \mathrm{nH}$ \\
\hline$L_{a 12}$ & $19.4 \mathrm{nH}$ \\
\hline$L_{a 23}$ & $9.6 \mathrm{nH}$ \\
\hline$C_{a 12}$ & $20 \mathrm{pF}$ \\
\hline$C_{a 23}$ & $3.23 \mathrm{pF}$ \\
\hline$X 1$ & 0.92 \\
\hline$M_{1}$ & 1.575 \\
\hline$M_{2}$ & 1.22 \\
\hline$M_{3}$ & 1.02 \\
\hline
\end{tabular}

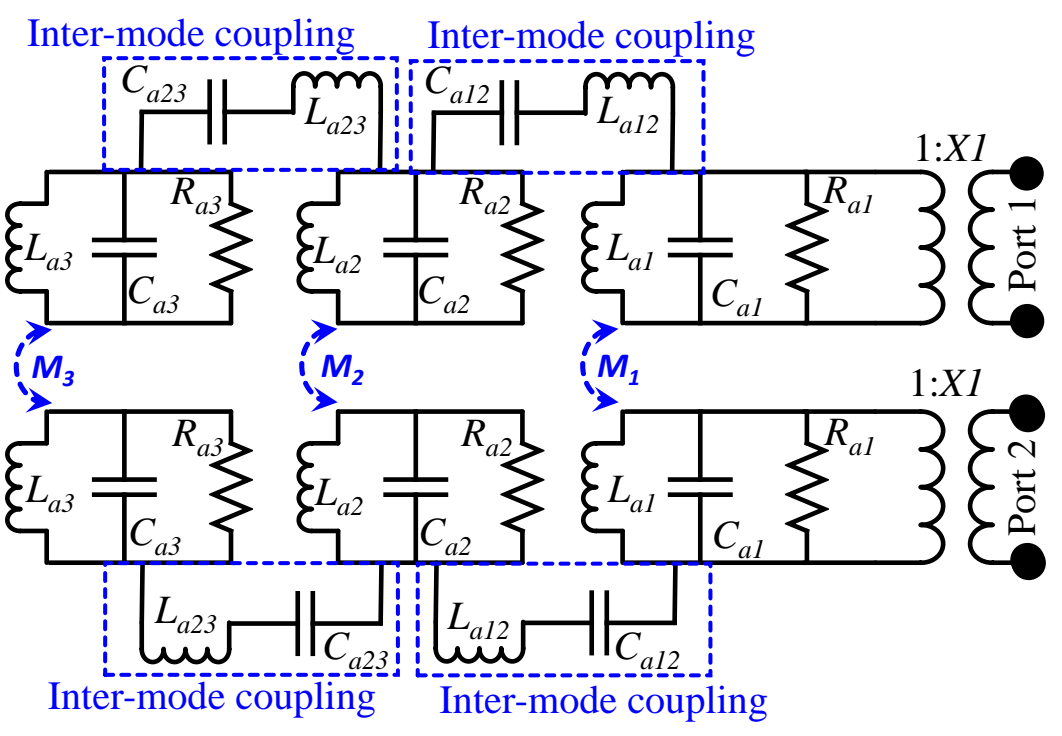

Figure 4. Lumped element equivalent circuit model of the UWB-MIMO system without decoupling structure.

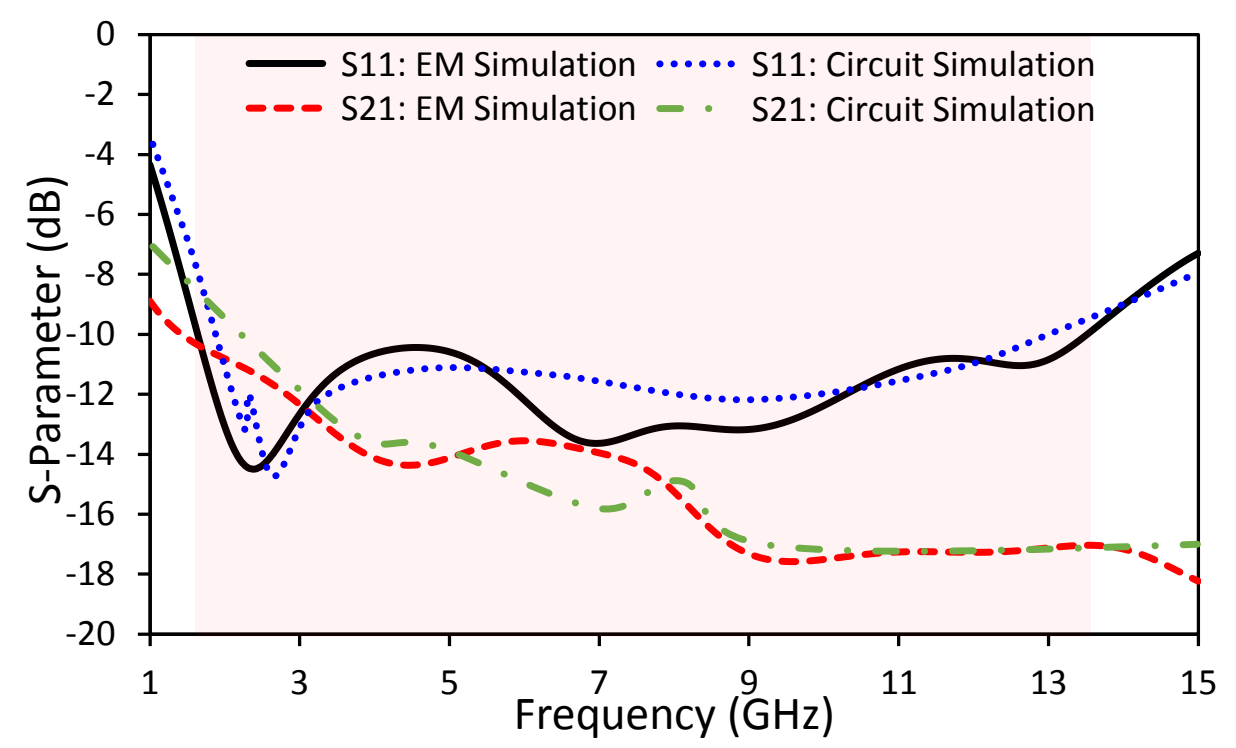

Figure 5. Lumped element equivalent circuit simulation comparison with EM simulation without decoupling structure. 


\subsection{UWB-MIMO Antenna System with Slotted Stub}

In this section, the equivalent circuit model for slotted stubs is presented. The slotted stubs are added within the antenna elements at the ground plane side to reduce the mutual coupling between the antennas, suppress the surface waves and near fields. To model accurately the proposed MIMO antenna system with the decoupling structure, the same assumptions regarding the radiating modes and inter-mode coupling are considered. In other words, three radiating modes and corresponding inter-mode couplings are modeled for the radaiting structures. The radiating modes are modeled by the combination of RLC circuits, transmission lines are modeled by impedance transformers, and inter-mode coupling is modeled by LC-tank circuits. Since the mutual coupling can be reduced by a band stop response by introducing transmission zeros within the operating range. The decoupling structure is modeled by the combination of RLC circuits. These RLC circuits are coupled with the radiating modes by $M_{1 d c}, M_{2 d c}$, and $M_{3 d c}$ coupling ratios. By using the coupling structure, the isolation for the proposed system is well below $20 \mathrm{~dB}$ for the whole bandwidth. The value of each component and the equivalent circuit model are depicted in Figure 6. The simulated results of the EM model and the circuit model are in good agreement, as shown in Figure 7.

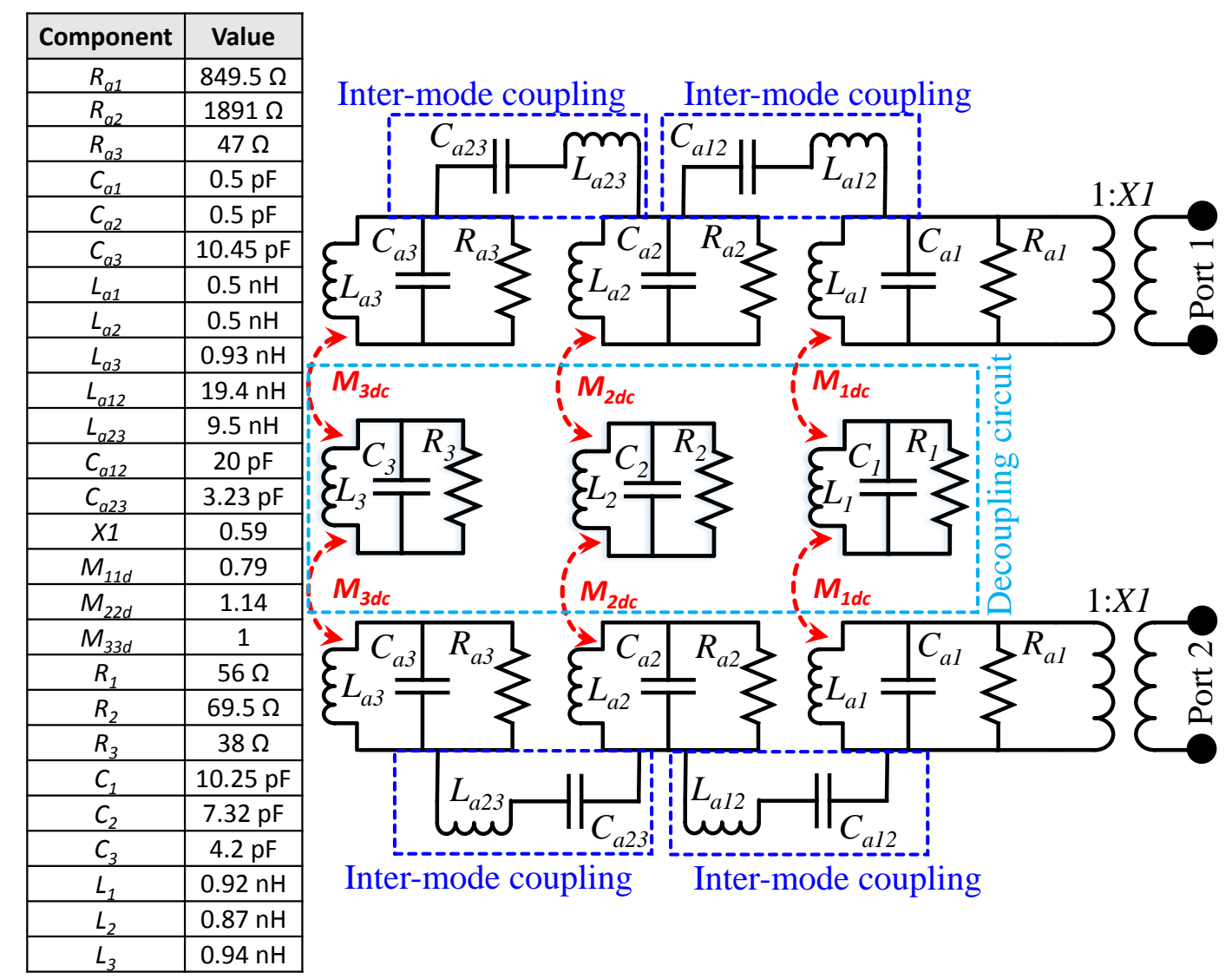

Figure 6. Lumped element equivalent circuit model of the UWB-MIMO system with decoupling structure. 


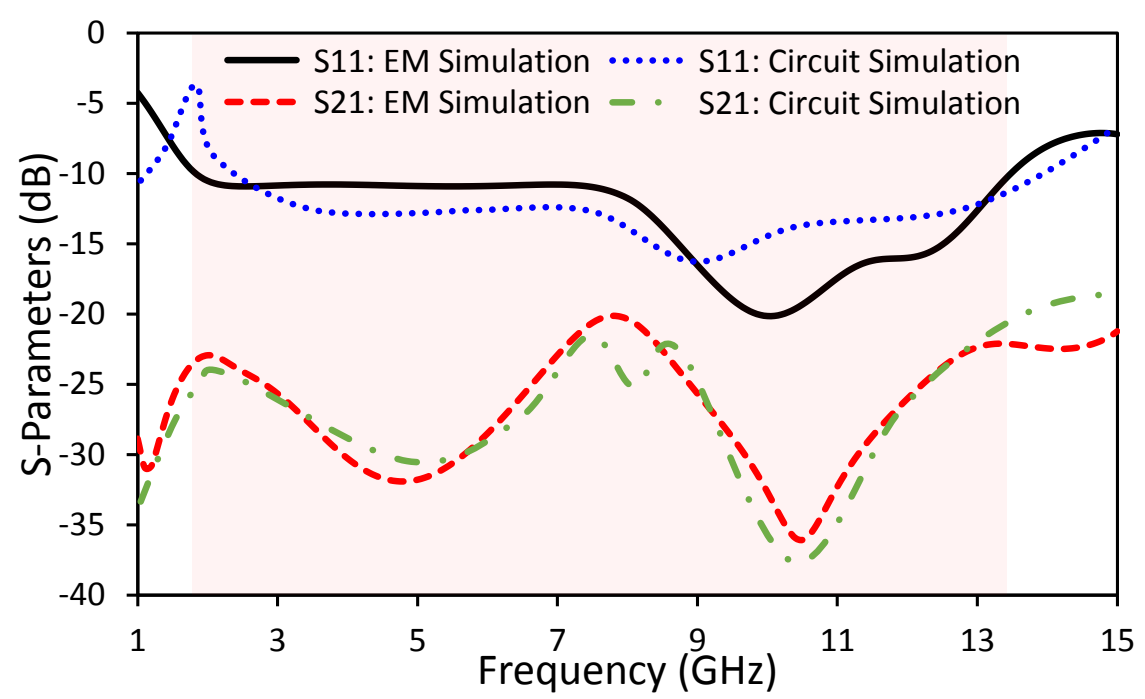

Figure 7. Lumped element equivalent circuit simulation comparison with EM simulation in the presence of decoupling structure.

\section{Results and Discussion}

The proposed MIMO antenna system with an isolation network was fabricated using the LPKF machine. The system was measured using a two-port vector network analyzer. The radiation patterns were measured in an anechoic chamber. By introducing the decoupling network, key performance parameters of the antenna were not affected. The simulated and measured S-parameters results for the proposed system are shown in Figure 8. The results were in good agreement. It can be seen that the isolation between the radiating elements was below $-20 \mathrm{~dB}$ within the whole operating range.

The slotted stubs were used to improve isolation between the antennas. When there was no decoupling network, the surface waves were coupled to the non-excited radiating element resulting in high mutual coupling. On the other hand, when the decoupling structure was incorporated within the elements, one can see that the surface waves and near fields were suppressed in the non-excited antenna. The surface waves and the near fields were concentrated within the decoupling structure resulting in high isolation between the antenna elements. This phenomenon can be observed in Figure 9. The surface current distribution with and without the slotted stubs at $10 \mathrm{GHz}$ is shown in Figure 9.

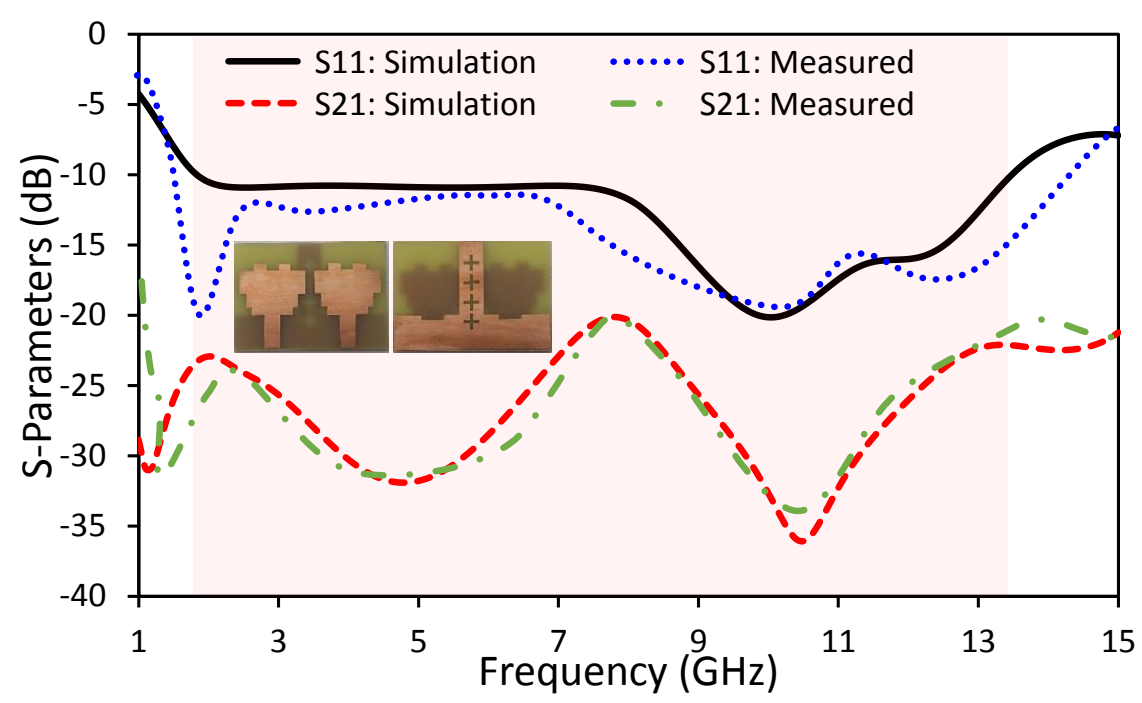

Figure 8. Simulated and measured S-parameters of the antenna. 


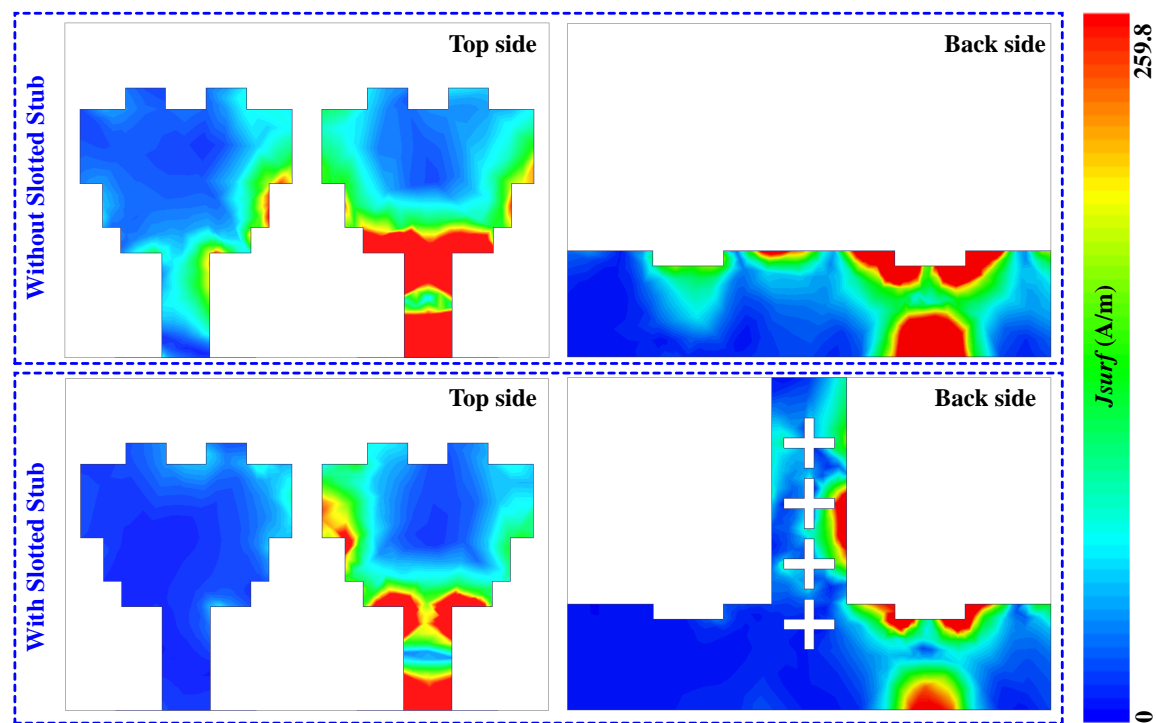

Figure 9. Surface current distribution with and without slotted stub at $10 \mathrm{GHz}$.

Gain is one of the key parameter of the antenna. The simulated and measured gain of the antenna is greater than $1.1 \mathrm{dBi}$ with a maximum value of $4.3 \mathrm{dBi}$ at $12 \mathrm{GHz}$. The simulated and measured gains are in good agreement for the whole operating bandwidth as shown in Figure 10. The far-field patterns of the proposed system is shown in Figure 11. The radiation patterns are shown for three different frequencies, i.e., 2.4, 5, and $10 \mathrm{GHz}$. The comparison between the simulated and measured $x z$ - and $y z$-plane radiation characteristics are shown in Figure 11. The results were in good agreement.

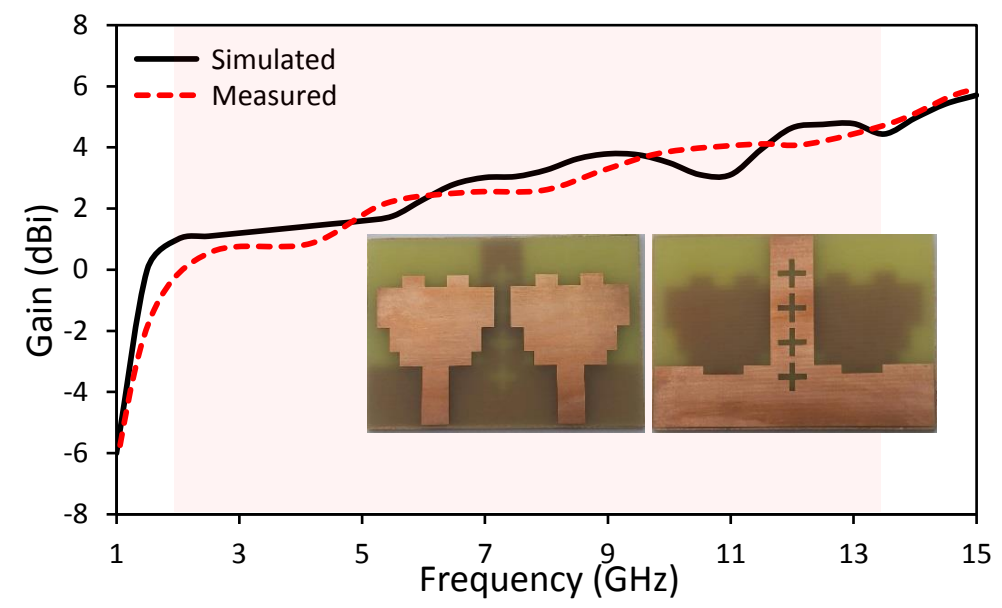

Figure 10. Simulated and measured peak gain of the antenna.

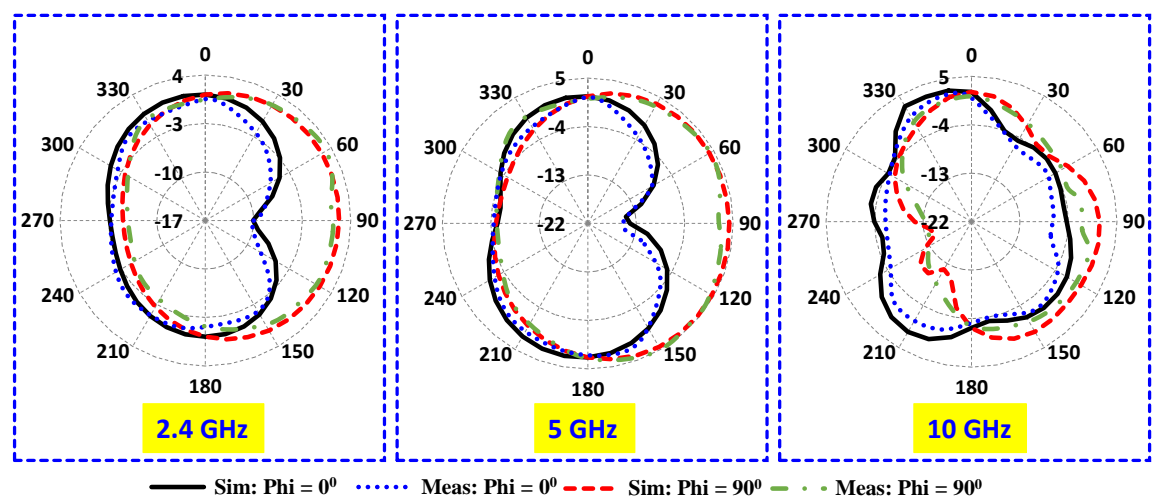

Figure 11. Radiation pattern of the antenna at 2.4, 5 and $10 \mathrm{GHz}$. 


\section{MIMO Parameters}

In this section, key performance parameters of a MIMO system are discussed. Envelope Correlation Coefficient (ECC) and Diversity Gain (DG) are one of the vital parameters of the MIMO system. ECC defines the effect of one antenna over the performance of the other antenna within a multiple antenna system. In other words, it measures how a member is affecting the performance of the other member within a system. ECC can be calculated either by using the S-parameters or radiation characteristics as represented in Equations (1) and (2) respectively. In this paper, ECC is calculated using Equation (2).

$$
\begin{gathered}
E C C=\frac{\left|S_{11}^{*} S_{12}+S_{22}^{*} S_{21}\right|^{2}}{\left[1-\left(\left|S_{11}\right|^{2}\right)+\left|S_{12}\right|^{2}\right]\left[1-\left(\left|S_{22}\right|^{2}\right)+\left|S_{21}\right|^{2}\right]} \\
E C C=\frac{\left.\mid \iint_{4 \pi}\left(\mathbf{B}_{i}(\theta, \phi)\right) \times \mathbf{B}_{j}(\theta, \phi)\right)\left.d \Omega\right|^{2}}{\left.\left.\iint_{4 \pi} \mid \mathbf{B}_{i}(\theta, \phi)\right)\left.\right|^{2} d \Omega \iint_{4 \pi} \mid \mathbf{B}_{j}(\theta, \phi)\right)\left.\right|^{2} d \Omega}
\end{gathered}
$$

where $S_{11} / S_{22}$ and $S_{21} / S_{12}$ are the reflection and transmission coefficient of the antenna. $\mathbf{B}_{i}(\theta, \phi)$ is the three dimensional radiation pattern upon excitation of the $i$-th antenna and $\mathbf{B}_{j}(\theta, \phi)$ is the three dimensional radiation pattern upon excitation of the $j$-th antenna, and $\Omega$ represents the solid angle.

On the other hand, the DG is the selection of the strongest signal from $N$ number of signals. It is calculated through the following equation.

$$
D G=10 \sqrt{1-(E C C)^{2}}
$$

The simulated ECC and DG for the proposed system is shown in Figure 12. It can be seen that the DG was more than $9.85 \mathrm{dBi}$ and the ECC was less than 0.15 within the band of interest. One of the important MIMO system parameters is Channel Capacity Loss (CCL). The measured and simulated CCL of the proposed system is depicted in Figure 13. It is observed that CCL was less than $0.06 \mathrm{bps} / \mathrm{Hz}$ for the whole operating bandwidth.

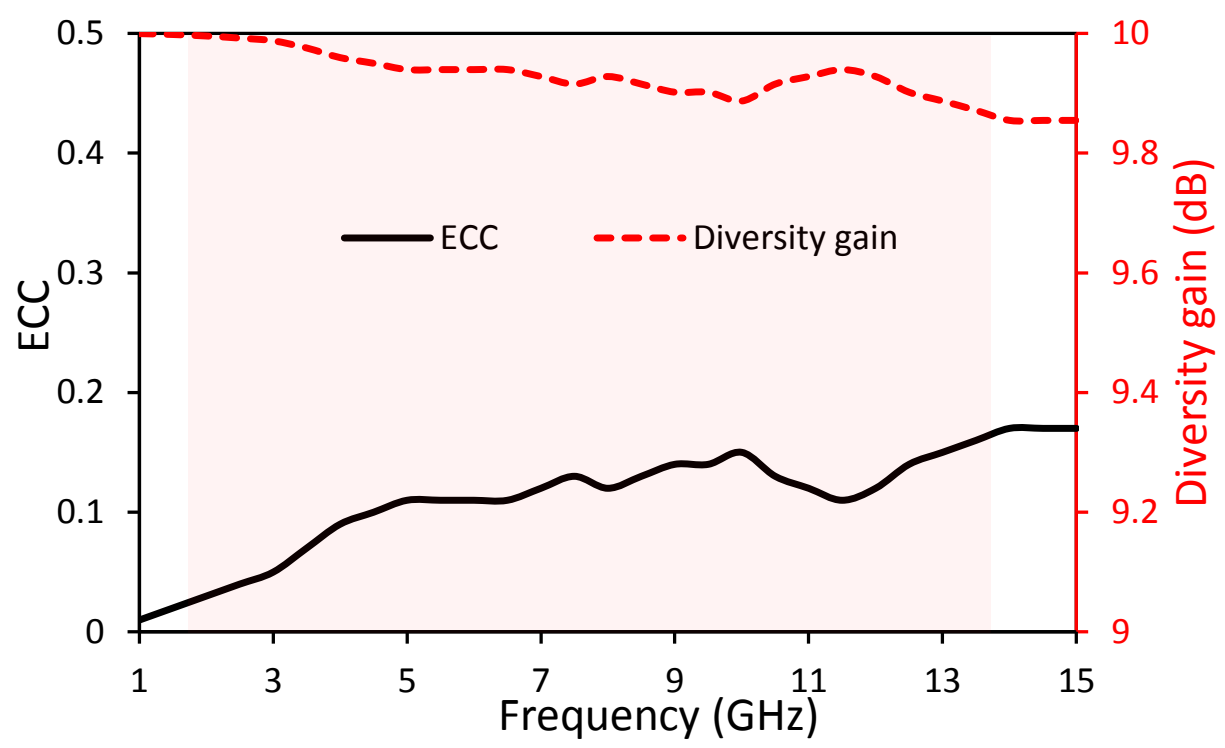

Figure 12. Envelope correlation coefficient (ECC) and Diversity Gain (DG) of the UWB-MIMO antenna system.

A detailed comparison between the proposed and published UWB-MIMO antenna is tabulated in Table 1. It is noticeable that the proposed antenna cover minimal dimensions, has large bandwidth, adequate gain value and high isolation. It is worth noticeable that the proposed antenna has high 
isolation even the patches has low edge-to-edge gap $(3 \mathrm{~mm})$. Moreover, we extracted circuit model in each step. The isolation and bandwidth enhancements phenomena is discussed using circuit theory.

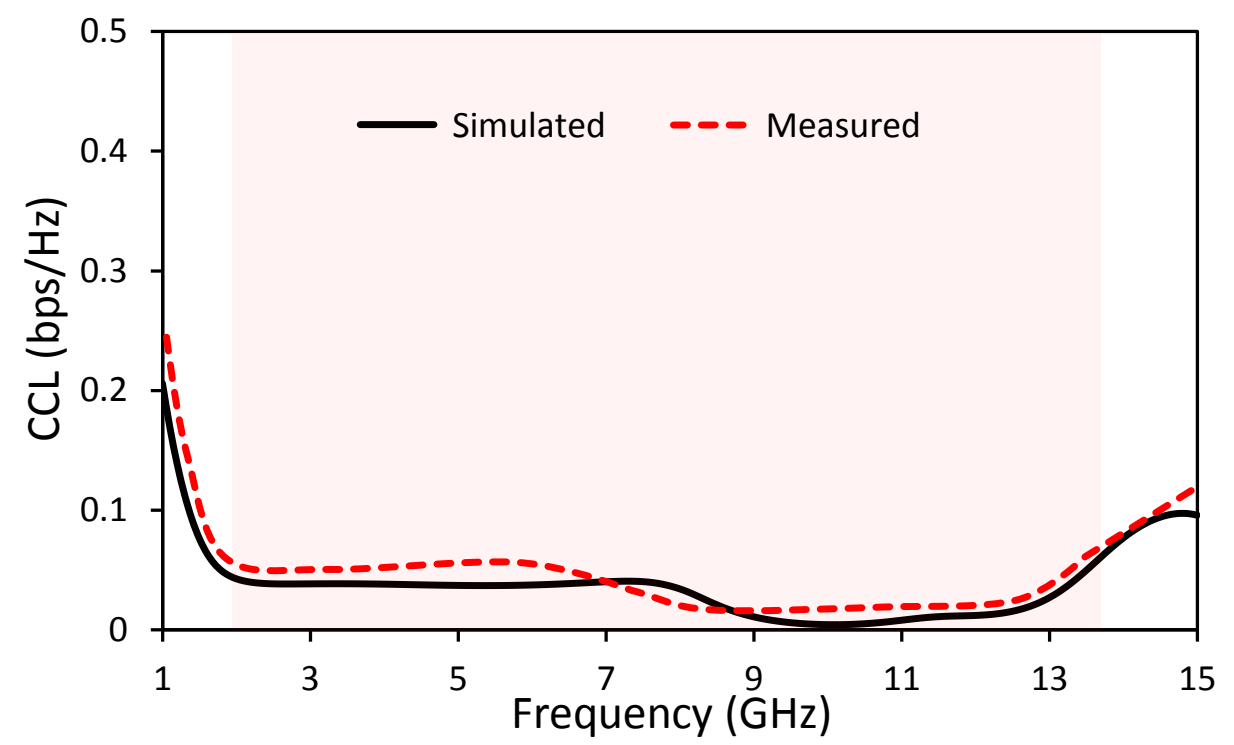

Figure 13. Simulated and measured CCL of the UWB-MIMO antenna system.

Table 1. Performance comparison with UWB-MIMO antennas.

\begin{tabular}{cccccccc}
\hline Ref. & $\begin{array}{c}\text { Size } \\
\left(\mathbf{m m}^{2}\right)\end{array}$ & $\begin{array}{c}\text { Edge-to-Edge } \\
\text { Gap }(\mathbf{m m})\end{array}$ & $\begin{array}{c}\text { Operating Frequency } \\
\text { Range } \mathbf{( G H z )}\end{array}$ & Isolation (dB) & Gain (dBi) & $\begin{array}{c}\text { Common } \\
\text { Ground }\end{array}$ & $\begin{array}{c}\text { Circuit } \\
\text { Model }\end{array}$ \\
\hline$[6]$ & $40 \times 80$ & NG & $4.5-8$ & $>25$ & $2-4$ & No & No \\
{$[7]$} & $27 \times 47$ & NG & $3.1-10.6$ & $>20$ & $2.8-5.4$ & Yes & No \\
{$[8]$} & $18 \times 36$ & 21.5 & $3-40$ & $>15$ & $0-9$ & Yes & No \\
{$[9]$} & $68 \times 35$ & NG & $3.1-10.6$ & 20 & $1.7-4.2$ & No & No \\
{$[10]$} & $81 \times 81$ & NG & $3.1-11.14$ & $>18$ & $4-8.48$ & No & No \\
{$[11]$} & $37 \times 45$ & 3 & $3.1-5$ & $>20$ & $>-2$ & Yes & No \\
{$[12]$} & $40 \times 68$ & 34 & $3.2-10.6$ & $>15$ & $3-5.5$ & Yes & No \\
{$[13]$} & $50 \times 30$ & NG & $2.5-14.5$ & $>20$ & $0.3-4.3$ & Yes & No \\
This Work & $33 \times \mathbf{4 8}$ & $\mathbf{3}$ & $\mathbf{2 - 1 3 . 7}$ & $>\mathbf{2 0}$ & $\mathbf{1 . 1}-\mathbf{4 . 3}$ & Yes & Yes \\
\hline
\end{tabular}

Designing a UWB-MIMO antenna has many challenges. The main challenges include achieving a wide bandwidth with omnidirectional patterns, high gain and acceptable isolation within radiating elements. Moreover, it is necessary to maintain the parameters of antenna before and after the decoupling structure. In this work, the isolation between the antennas is improved by etching slots in the ground plane and omnidirectional patterns are achieved for the whole frequency range. The proposed antenna cannot be used for the base station because the base station requires high gain antennas. In other words, this antenna is suitable for mobile devices due to its miniature nature and omnidirectional patterns. One of the limitations is that the phase and magnitude of the radiated fields are frequency dependent. UWB antennas are a combination of different resonances within a frequency range. The impedance, surface waves, and radiated fields vary and affect the performance of the antenna. This makes the response of the antenna unpredictable. By deploying different techniques like DGS, EBG, and slots within the antenna and/or ground plane, the response can be controlled.

\section{Conclusions}

In this article, an UWB MIMO antenna system with an isolation of $-20 \mathrm{~dB}$ is presented. The UWB response is achieved by designing a stepped-shaped antenna while the isolation is improved by using slotted stubs etched in the ground plane within the radiating elements. The system is fabricated on an FR4 substrate. The circuit theory is used to model the circuit model and compared the results with the 
EM model. The simulated design is fabricated and key performance parameters are calculated and measured. The simulated, measured, and the circuit model results are in good agreement. It is found that ECC and DG for the proposed system are 0.15 and $9.85 \mathrm{dBi}$ respectively. The CCL is less than $0.06 \mathrm{bps} / \mathrm{Hz}$ for the whole operating bandwidth. Future work will focus on increasing the number of transmitting and receiving antennas to enhance the throughput. Moreover, the coupling effect between the antenna elements can be enhanced by combining the proposed method with any other method. In fact, such a decoupling method will be helpful to develop universal guidelines for compact UWB-MIMO antenna systems.

Author Contributions: design and concept, A.A. and A.I.; methodology, A.A. A.I.; investigation, A.I. and S.H.K.; resources, A.I.; writing—original draft preparation, A.A., A.I., A.S., J.S. and S.H.K.; writing—review and editing, A.A., A.I., A.S., J.S., A.A.A. and S.H.K.; validation, A.A., A.I., A.S., J.S., A.A.A., S.H.K. M.A., E.L. and F.F.; supervision, A.A., A.I., A.S., J.S., A.A.A., S.H.K. M.A., E.L. and F.F.; project administration, A.A., A.I., A.S., J.S., A.A.A., S.H.K. M.A., E.L. and F.F. All authors have read and agreed to the published version of the manuscript.

Funding: The authors extend their appreciation to the Deanship of Scientific Research at Majmaah University for funding this work under Project Number RGP-2019-32.

Acknowledgments: This work is partially supported by RTI2018-095499-B-C31, Funded by Ministerio de Ciencia, Innovación y Universidades, Gobierno de España (MCIU/AEI/FEDER,UE).

Conflicts of Interest: The authors declare no conflict of interest.

\section{References}

1. Alibakhshikenari, M.; Virdee, B.S.; See, C.H.; Abd-Alhameed, R.A.; Falcone, F.; Limiti, E. Surface wave reduction in antenna arrays using metasurface inclusion for MIMO and SAR systems. Radio Sci. 2019, 54, 1067-1075. [CrossRef]

2. Alibakhshikenari, M.; Virdee, B.S.; See, C.H.; Abd-Alhameed, R.A.; Falcone, F.; Limiti, E. High-isolation leaky-wave array antenna based on CRLH-metamaterial implemented on SIW with $\pm 30^{\circ}$ frequency beam-scanning capability at millimetre-waves. Electronics 2019, 8, 642. [CrossRef]

3. Alibakhshikenari, M.; Virdee, B.S.; Limiti, E. Triple-band planar dipole antenna for omnidirectional radiation. Microw. Opt. Technol. Lett. 2018, 60, 1048-1051. [CrossRef]

4. Alibakhshikenari, M.; Virdee, B.S.; See, C.H.; Abd-Alhameed, R.; Ali, A.; Falcone, F.; Limiti, E. Wideband printed monopole antenna for application in wireless communication systems. IET Microw. Antennas Propag. 2018, 12, 1222-1230. [CrossRef]

5. Alibakhshikenari, M.; Khalily, M.; Virdee, B.S.; See, C.H.; Abd-Alhameed, R.A.; Limiti, E. Mutual-coupling isolation using embedded metamaterial EM bandgap decoupling slab for densely packed array antennas. IEEE Access 2019, 7, 51827-51840. [CrossRef]

6. Jabire, A.H.; Zheng, H.X.; Abdu, A.; Song, Z. Characteristic mode analysis and design of wide band MIMO antenna consisting of metamaterial unit cell. Electronics 2019, 8, 68. [CrossRef]

7. Khan, M.S.; Shafique, M.F.; Capobianco, A.; Autizi, E.; Shoaib, I. Compact UWB-MIMO antenna array with a novel decoupling structure. In Proceedings of the 2013 10th International Bhurban Conference on Applied Sciences \& Technology (IBCAST), Islamabad, Pakistan, 15-19 January 2013; pp. 347-350.

8. Irshad Khan, M.; Khattak, M.I.; Rahman, S.U.; Qazi, A.B.; Telba, A.A.; Sebak, A. Design and Investigation of Modern UWB-MIMO Antenna with Optimized Isolation. Micromachines 2020, 11, 432. [CrossRef]

9. Li, W.T.; Hei, Y.Q.; Subbaraman, H.; Shi, X.W.; Chen, R.T. Novel printed filtenna with dual notches and good out-of-band characteristics for UWB-MIMO applications. IEEE Microw. Wirel. Compon. Lett. 2016, 26, 765-767. [CrossRef]

10. Srivastava, K.; Kumar, A.; Kanaujia, B.K.; Dwari, S.; Kumar, S. A CPW-fed UWB MIMO antenna with integrated GSM band and dual band notches. Int. J. RF Microw. Comput. Aided Eng. 2019, 29 , e21433. [CrossRef]

11. See, T.S.; Chen, Z.N. An ultrawideband diversity antenna. IEEE Trans. Antennas Propag. 2009, 57, 1597-1605. [CrossRef]

12. Najam, A.I.; Duroc, Y.; Tedjni, S. UWB-MIMO antenna with novel stub structure. Prog. Electromagn. Res. 2011, 19, 245-257. [CrossRef] 
13. Iqbal, A.; Saraereh, O.A.; Ahmad, A.W.; Bashir, S. Mutual coupling reduction using F-shaped stubs in UWB-MIMO antenna. IEEE Access 2017, 6, 2755-2759. [CrossRef]

14. Saha, T.K.; Knaus, T.N.; Khosla, A.; Sekhar, P.K. A CPW-fed flexible UWB antenna for IoT applications. Microsyst. Technol. 2018, 24, 1-7. [CrossRef]

15. Jan, N.A.; Kiani, S.H.; Muhammad, F.; Sehrai, D.A.; Iqbal, A.; Tufail, M.; Kim, S. V-Shaped Monopole Antenna with Chichena Itzia Inspired Defected Ground Structure for UWB Applications. CMC Comput. Mater. Contin. 2020, 65, 19-32.

16. Sehrai, D.A.; Abdullah, M.; Altaf, A.; Kiani, S.H.; Muhammad, F.; Tufail, M.; Irfan, M.; Glowacz, A.; Rahman, S. A Novel High Gain Wideband MIMO Antenna for 5G Millimeter Wave Applications. Electronics 2020, 9, 1031. [CrossRef]

17. Simorangkir, R.B.; Kiourti, A.; Esselle, K.P. UWB wearable antenna with a full ground plane based on PDMS-embedded conductive fabric. IEEE Antennas Wirel. Propag. Lett. 2018, 17, 493-496. [CrossRef]

18. Yang, D.; Hu, J.; Liu, S. A low profile UWB antenna for WBAN applications. IEEE Access 2018, 6, 25214-25219. [CrossRef]

19. Li, M.; Luk, K.M. A differential-fed UWB antenna element with unidirectional radiation. IEEE Trans. Antennas Propag. 2016, 64, 3651-3656. [CrossRef]

20. Iqbal, A.; Saraereh, O.A.; Bouazizi, A.; Basir, A. Metamaterial-based highly isolated MIMO antenna for portable wireless applications. Electronics 2018, 7, 267. [CrossRef]

21. Iqbal, A.; Basir, A.; Smida, A.; Mallat, N.K.; Elfergani, I.; Rodriguez, J.; Kim, S. Electromagnetic bandgap backed millimeter-wave MIMO antenna for wearable applications. IEEE Access 2019, 7, 111135-111144. [CrossRef]

22. Elfergani, I.; Rodriguez, J.; Iqbal, A.; Sajedin, M.; Zebiri, C.; AbdAlhameed, R.A. Compact millimeter-wave MIMO antenna for 5G applications. In Proceedings of the 2020 14th European Conference on Antennas and Propagation (EuCAP), Copenhagen, Denmark, 15-20 March 2020; pp. 1-5.

23. Elfergani, I.; Iqbal, A.; Zebiri, C.; Basir, A.; Rodriguez, J.; Sajedin, M.; de Oliveira Pereira, A.; Mshwat, W.; Abd-Alhameed, R.; Ullah, S. Low-Profile and Closely Spaced Four-Element MIMO Antenna for Wireless Body Area Networks. Electronics 2020, 9, 258. [CrossRef]

24. Iqbal, A.; Smida, A.; Alazemi, A.J.; Waly, M.I.; Mallat, N.K.; Kim, S. Wideband Circularly Polarized MIMO Antenna for High Data Wearable Biotelemetric Devices. IEEE Access 2020, 8, 17935-17944. [CrossRef]

25. Kiani, S.H.; Mahmood, K.; Altaf, A.; Cole, A.J. Mutual coupling reduction of MIMO antenna for satellite services and radio altimeter applications. Int. J. Adv. Comput. Sci. Appl. 2018, 9, 23-26. [CrossRef]

26. Iqbal, A.; Altaf, A.; Abdullah, M.; Alibakhshikenari, M.; Limiti, E.; Kim, S. Modified U-Shaped Resonator as Decoupling Structure in MIMO Antenna. Electronics 2020, 9, 1321. [CrossRef]

27. Altaf, A.; Alsunaidi, M.A.; Arvas, E. A novel EBG structure to improve isolation in MIMO antenna. In Proceedings of the 2017 USNC-URSI Radio Science Meeting (Joint with AP-S Symposium), San Diego, CA, USA, 9-14 July 2017; pp. 105-106.

28. Jaglan, N.; Gupta, S.D.; Thakur, E.; Kumar, D.; Kanaujia, B.K.; Srivastava, S. Triple band notched mushroom and uniplanar EBG structures based UWB MIMO/Diversity antenna with enhanced wide band isolation. AEU-Int. J. Electron. Commun. 2018, 90, 36-44. [CrossRef]

29. Gorai, A.; Ghatak, R. Utilization of Shorted Fractal Resonator topology for high isolation and ELC resonator for band suppression in compact MIMO UWB antenna. AEU-Int. J. Electron. Commun. 2020, 113, 152978. [CrossRef]

30. Li, J.F.; Chu, Q.X.; Li, Z.H.; Xia, X.X. Compact dual band-notched UWB MIMO antenna with high isolation. IEEE Trans. Antennas Propag. 2013, 61, 4759-4766. [CrossRef]

31. Zhang, S.; Lau, B.K.; Sunesson, A.; He, S. Closely-packed UWB MIMO/diversity antenna with different patterns and polarizations for USB dongle applications. IEEE Trans. Antennas Propag. 2012, 60, 4372-4380. [CrossRef]

32. Cruz, J.D.N.; Serres, A.J.R.; de Oliveira, A.C.; Xavier, G.V.R.; de Albuquerque, C.C.R.; da Costa, E.G.; Freire, R.C.S. Bio-inspired Printed Monopole Antenna Applied to Partial Discharge Detection. Sensors 2019, 19, 628. [CrossRef]

33. Lin, G.S.; Sung, C.H.; Chen, J.L.; Chen, L.S.; Houng, M.P. Isolation improvement in UWB MIMO antenna system using carbon black film. IEEE Antennas Wirel. Propag. Lett. 2016, 16, 222-225. [CrossRef] 
34. Iqbal, A.; Selmi, M.A.; Abdulrazak, L.F.; Saraereh, O.A.; Mallat, N.K.; Smida, A. A Compact Substrate Integrated Waveguide Cavity-Backed Self-Triplexing Antenna. IEEE Trans. Circuits Syst. II Express Briefs 2020. [CrossRef]

35. Iqbal, A.; Alazemi, A.J.; Mallat, N.K. Slot-DRA-based independent dual-band hybrid antenna for wearable biomedical devices. IEEE Access 2019, 7, 184029-184037. [CrossRef]

36. Iqbal, A.; Bouazizi, A.; Kundu, S.; Elfergani, I.; Rodriguez, J. Dielectric resonator antenna with top loaded parasitic strip elements for dual-band operation. Microw. Opt. Technol. Lett. 2019, 61, 2134-2140. [CrossRef]

(C) 2020 by the authors. Licensee MDPI, Basel, Switzerland. This article is an open access article distributed under the terms and conditions of the Creative Commons Attribution (CC BY) license (http://creativecommons.org/licenses/by/4.0/). 